\title{
Writing nonsense: the interaction between lexical and sublexical knowledge in the priming of nonword spelling
}

\author{
Daisy H. Martin • Christopher Barry
}

Published online: 8 May 2012

(C) Psychonomic Society, Inc. 2012

\begin{abstract}
The task of spelling nonwords to dictation necessarily requires the operation of a sublexical or assembled sound-to-spelling conversion process. We report an experiment that shows a clear lexical priming effect on nonword spelling (e.g., /vi:m/ was spelled as VEME more often following the prime word "theme" and as VEAM more often following "dream"), which was larger for lexically low-probability (or low-contingency) than for common (or high-contingency) spellings. Priming diminished when an unrelated word intervened between the prime word and target nonword and did so more for the production of low- than for high-contingency spellings. We interpret these results within an interactive model of spelling production that proposes feedback from the graphemic level to both the lexical and assembled spelling processes.
\end{abstract}

Keywords Spelling · Nonword spelling · Orthography · Lexical priming $\cdot$ Dual-route model

There are two broad ways in which people can spell words: They may retrieve learned lexical knowledge of how individual words are spelled (e.g., /fist $/=$ fist and $/$ sist $/=c y s t$ ), or they may apply sublexical knowledge of how individual sounds are generally spelled (e.g., words beginning with /t/ are usually spelled with T-, despite the exception pterodac$t y l)$. The first method would work for all known words but

This research was supported by a United Kingdom Economic and Social Science Research Council research studentship awarded to Daisy Martin.

D. H. Martin · C. Barry $(\bowtie)$

Department of Psychology, University of Essex,

Wivenhoe Park,

Colchester CO4 3SQ, UK

e-mail: cbarry@essex.ac.uk could not provide spellings for nonwords (or new words). The second method would work for nonwords and for words with predictable (or "regular") spellings but would produce incorrect, although phonologically plausible, spellings for "irregular" words (e.g., "learn" $\rightarrow$ lern, lirn, or lurn). These two methods are instantiated as the separate processes of the dual-route model of spelling (e.g., Barry, 1994; Ellis, 1982; Kreiner \& Gough, 1990; Morton, 1980), which proposes that they operate in parallel. The lexical route retrieves spellings from an orthographic lexicon, and the assembled route generates spellings by a process of sublexical sound-to-spelling conversion. The outputs of the two routes converge at a graphemic level, which has been called the graphemic output buffer (e.g., Rapp \& Caramazza, 1997) and orthographic working memory (Jones, Folk, \& Rapp, 2009). Motor output processes that drive writing, typing, and oral spelling operate upon graphemiclevel representations.

The dual-route model of spelling is often expressed only in symbolic terms but is also found in interactive (Rapp, Epstein, \& Tainturier, 2002) and implemented connectionist (Houghton \& Zorzi, 2003) spelling models. It is supported by cognitive neuropsychological evidence that suggests that the two processing routines are functionally separable, in that brain damage can selectively impair one but leave the other operational (Barry, 1994; Tainturier \& Rapp, 2000), but whether these routines are functionally independent in normal spelling is a separate question. The present article is concerned with investigating the interaction between the lexical and assembled processes in spelling production in literate adults.

The task of spelling nonwords to dictation necessarily requires an assembled process, but the nature of its operation has not been precisely specified. Sound-to-spelling relationships are notoriously inconsistent in English; for 
example, /i:/ is spelled in over a dozen different ways (as in leaf, beef, thief, theme, me, key, quay, ski, Keith, people, foetal, thusly, and Wii). Since phoneme-to-grapheme relationships for vowels are widely distributed, Barry and Seymour (1988) favored the term sound-to-spelling contingency and referred to high- and low-contingency spellings (i.e., lexically common vs. rare) rather than "regular" and "irregular" spellings.

Does assembled spelling operate autonomously, or is it open to lexical influence? Campbell (1983) presented lists of spoken words and nonwords to participants instructed to write down only the nonwords and found a substantial lexical priming effect: $71 \%$ of nonwords were spelled with the same pattern as their prime word. For example, people who heard "cheat-/fri:t/" tended to spell the nonword as FREAT, whereas those who heard "greet-/fri:t/" tended to spell it as FREET. Lexical priming effects have also been found in children (Campbell, 1985; Nation \& Hulme, 1996), in both good and poor adult spellers (Burden, 1989), and in spellers of Spanish (Cuetos, 1993), Italian (Barry \& De Bastiani, 1997), and Welsh (Barry, 1992), whose orthographies have more consistent sound-to-spelling relationships than does English. Barry and Seymour (1988) found equal priming for both high- and low-contingency spellings (e.g., "fruit-/pu:t" $\rightarrow$ PRUIT), but they used different stimulus nonwords in their high- and low-contingency priming conditions, a shortcoming that is overcome in the present study.

In addition to finding priming from rhyming words (e.g., "said-/ged/" $\rightarrow$ GAID), Folk and Rapp (2004) also found a smaller orthographic priming effect from nonrhyming words with the same target spelling (e.g., "paid-/ged/" $\rightarrow$ GAID). Thus, there are at least two sources of the lexical priming effect: (1) changes to the probability of selecting a particular spelling-to-sound correspondence (e.g., "said" would prime the /e/ => AI correspondence) and (2) residual (or persisting) graphemic-level activation from the prime word (e.g., "paid" would activate the letters -AID, making them more likely to be selected). Priming from rhyming words could reflect both these sources, whereas priming from orthographically similar words reflects only the graphemic-level source.

Our understanding of the temporal dynamics of these priming processes, which reflect the interaction between lexical and assembled spelling, may be advanced by the study of the duration of priming effects. Perry (2003) found that primed spellings were produced on $72.5 \%$ of trials when the prime word immediately preceded the target nonword, which reduced to $62.9 \%$ when one filler nonword intervened between the prime and target, and then flattened at $61.5 \%$ when two filler nonwords intervened. On the assumption that an intervening item has a greater effect upon the graphemic-level contribution to the overall priming effect, Perry's results show that residual graphemic-level activation lasts only a short time, relative to the longer lasting priming of the selection of spelling correspondences.

Perry (2003) used only high-contingency spellings in his prime words. Our study investigated the expected reduction of the priming effect by presenting an unrelated word between a prime word with either a high- or a low-contingency spelling and a target nonword. The relative balance of the contributions of graphemic and spelling correspondence activation to the priming effect is likely to be different for the production of high- and low-contingency spellings. We expect that the role of graphemic activation will be larger for high- than for low-contingency spellings. This is because the overall degree of graphemic activation from the prime word will reflect the sum of the contributions of both the lexical and assembled routes, which will produce more congruent activation for high-contingency words (such as LEAF) than for low-contingency words (such as THIEF, where the assembled route would activate EA more than IE). Since the presence of an intervening item affects persisting graphemic activation more than spelling correspondences, it should therefore have a larger effect on the production of low- than of high-contingency spellings.

Any increase in activation levels of recently used spellings might be expected to be more powerful for rarer than for more common correspondences, since these have a lower base rate of production and, so, have greater scope for improvement. In a variety of domains, priming effects have been observed to be larger for lower-frequency items; Reitter, Keller, and Moore (2011) referred to this as the "inverse frequency effect." For example, syntactic priming is larger for less frequent structures (Scheepers, 2003), and there is larger repetition priming of word recognition for low- than for high-frequency words (e.g., Scarborough, Cortese, \& Scarborough, 1977).

The combination of these factors leads us to predict that presenting an unrelated word between the prime and target nonword will have a larger effect for the production of lowthan of high-contingency spellings. The present study comprises two empirical investigations of nonword spelling. The first was a control task in which only nonwords were presented. This free-spelling task used the same nonwords as in the priming task and so provides a measure of the baseline frequency of the production of particular spellings, against which priming effects can be compared. ${ }^{1}$ In the priming task, participants heard a list of words and nonwords and

\footnotetext{
${ }^{1}$ Our use of a separate control group of participants to determine this baseline might be considered to be less sensitive for examining priming effects than a related design would be. However, Perry (2003) compared priming with a control condition (in which nonwords were preceded by unrelated words) in a within-participants, counterbalanced design and found "very similar results to using a prime minus baseline design, as done by Barry and Seymour" (p. 521).
} 
were required to write only the nonwords. (Flippantly, this could be called the "lecture task," in which student participants write down only the nonsense they don't already know!) Two variables were manipulated: the sound-tospelling contingency of the prime word and whether the prime immediately preceded the target nonword or whether there was an unrelated word intervening between the two. There were four conditions: (1) high-contingency, immediate (e.g., "dream, /vi:m/"); (2) high-contingency, with intervening (e.g., "dream, pip, /vi:m/"); (3) lowcontingency, immediate (e.g., "theme, /vi:m/"); and (4) low-contingency, with intervening (e.g., "theme, pip, /vi:m/"). The experiment was designed to assess the relative decay of priming for the production of high- and low-contingency spellings.

\section{Method}

Participants For the control task, approximately 70 undergraduates agreed to participate at the end of a psychology lecture. They were asked to state their first, native language and their gender and age and to indicate whether they had any reading or hearing problems. Data were analyzed only from the 60 students (46 women and 14 men; mean age $=20.4$ years) who completed the task, had English as their first language, and did not report any problems. For the experimental task, 40 undergraduate volunteers ( 22 women and 18 men), with a mean age of 20.7 years, participated. They were tested individually. All were native speakers of English and self-reported as being "not dyslexic."

Stimulus materials Sixteen critical sets of monosyllabic stimuli were selected such that each set comprised a target nonword and two rhyming words (e.g., /vi:m/, dream, theme), where one word has a high-contingency and one a low-contingency spelling of its vowel (see the Appendix). The spellings were selected from Barry and Seymour's (1988) analysis of phoneme-to-spelling relationships. The high-contingency spellings occurred in $39.7 \%$ of words with these vowels, and the low-contingency spellings occurred in only 4.1 \%. In Ziegler, Stone, and Jacobs's (1997) analysis of the spellings of phonological rimes, the highcontingency spellings occurred, on average, in $81.5 \%$ of words, and the low-contingency spellings occurred in only $9.9 \%$. There was no reliable difference between the word frequencies of the high- and low-contingency primes, $t(30)=1.21$.

All the stimulus nonwords contained vowels that are spelled inconsistently in words (e.g., /vi:m/ could be spelled plausibly as VEAM, VEEM, VIEM, or VEME, as well as others). However, analyses were restricted to the production of only the two critical spellings for each nonword that were in their respective prime words. Thus, for /vi:m/, the critical high- and low-contingency spellings analyzed were EA and E-E (since the primes for this nonword were dream and theme), whereas for /vi:f/, the critical spellings analyzed were EE and IE (since the primes were beef and thief). This stringent procedure was applied throughout.

In addition to the critical stimuli, a number of filler words and nonwords were also used (which ensured that presentation of nonwords with the same vowel was separated as much as possible). All fillers were monosyllabic and contained vowels that are spelled predictably in words. For the free-spelling task, only nonwords were presented. The 16 critical nonwords were intermixed with 32 filler nonwords. For the experimental task, the critical nonwords were presented with prime words. Each target nonword was presented only once to each participant, and the assignment of the stimuli to the four conditions was counterbalanced over four subgroups of ten participants. The intervening items for the critical stimuli were all words containing predictably spelled vowels. In addition, there were 48 nonword and 16 word fillers, whose presence was an attempt to reduce strategic processes in performing the experimental task. The 16 critical stimuli were embedded with fillers such that no items with the same critical vowels occurred next to each other (apart, of course, from the rhyming prime-target pairs).

Procedure Participants in the control task were instructed that they would hear a list of only nonwords and that their task was to spell each nonword in "the first natural way that comes to mind." The stimulus list was pronounced item by item by the second author in his Southern English accent at 3-s intervals.

Participants in the experimental group were tested individually and were instructed that they would hear a list of intermixed words and nonwords. They were given a response sheet and were told that if they heard what they thought was a real English word, they should put a tick, but if they heard a nonword, they should "write it down in a way that seems natural." The first author, who had recruited each participant, pronounced the stimuli in her Southern English accent, item by item, at 3-s intervals.

\section{Results}

Only spellings of the target vowel phonemes in the experimental 16 nonwords were analyzed. In the control task, $49.6 \%$ of all responses contained the critical highcontingency spellings, and only $3.8 \%$ contained the critical low-contingency spellings (a clearly significant difference; $\left.t_{\mathrm{s}}(39)=24.6, t_{\mathrm{i}}(15)=5.5, p<.0001\right)$. Only $3 / 960$ trials were 
not spelled at all, but there were $46.3 \%$ other spellings produced, the vast majority of which involved alternative high-contingency spellings - for example, /vi:m/ spelled as VEEM or VIEM, rather than the critical high-contingency spelling VEAM (as in its prime dream) or the critical lowcontingency spelling VEME (as in theme). In the experimental task, responses were excluded when the prime word was actually written or when the target nonword was not written; these accounted for only 14/640 trials. The spellings produced were classified as having the critical highcontingency spelling, the critical low-contingency spelling, or some other spelling. As in the control condition, most "other" spellings contained an alternative high-contingency spelling.

Table 1 presents the results of the two tasks, and Fig. 1 shows the priming effects calculated by subtracting the production of critical spelling patterns in the control, free-spelling task from those in the priming task. The priming effect was larger for the production of low- than of high-contingency spellings and was reduced when a filler item intervened between the prime and target, and this reduction was larger for the production of low-contingency (48.7-32.5) than of highcontingency spellings (26.7-21.7).

For each participant and for each item, priming effects in each condition were calculated by subtracting the percentage of the critical high- and low-contingency spellings produced in the experimental task from those in the control, free-spelling task. (For the analysis by participants, the mean of the control group in each condition was subtracted from each participant's score in that condition in the experimental group. For the analysis by items, for each nonword, the mean of all participants' scores in the control group was subtracted from the mean of all participants' scores in the experimental group.) These values were analyzed by $2 \times 2$ related ANOVAs with the factors of spelling contingency and position of the prime word. The main effect of contingency was significant, $F_{\mathrm{s}}(1,39)=17.1, M S E=0.067, p<.001$,

Table 1 Percentage of spellings produced for the vowels in the critical nonwords in each condition

\begin{tabular}{llll}
\hline & \multicolumn{2}{l}{$\%$ spellings produced } \\
\cline { 2 - 4 } & High-con. & Low-con. & $\begin{array}{l}\text { Other and } \\
\text { excluded }\end{array}$ \\
\hline Experimental conditions & & & \\
High-con. $\rightarrow$ nonword & 76.3 & 1.9 & 21.8 \\
High-con. $\rightarrow$ filler $\rightarrow$ nonword & 71.3 & 1.9 & 26.8 \\
Low-con. $\rightarrow$ nonword & 28.1 & 52.5 & 19.4 \\
Low-con. $\rightarrow$ filler $\rightarrow$ nonword & 35.0 & 36.3 & 28.7 \\
Free-spelling, control task & 49.6 & 3.8 & 46.6 \\
\hline
\end{tabular}

Note. High-con., high contingency; Low-con., low contingency
$F_{\mathrm{i}}(1,15)=7.3, M S E=5.915, p<.01$; the priming effects were larger for the production of low- than for highcontingency spellings. The main effect of position was significant by participants, $F_{\mathrm{s}}(1,39)=7.0, M S E=0.080, p<.05$, and approached significance by items, $F_{\mathrm{i}}(1,15)=3.03, M S E=$ $0.067, p=.09$, but this was modified by a significant interaction between the two variables, $F_{\mathrm{s}}(1,39)=6.6, M S E=0.029$, $p<.01, F_{\mathrm{i}}(1,15)=3.6, M S E=2.429, p<.05$; the effect of the position of the prime word was larger for the priming of lowthan of high-contingency spellings.

\section{Discussion}

Writing nonwords to dictation necessarily requires sublexical, assembled spelling, and the present study has revealed three important features of nonword spelling. First, there was a clear effect of sound-to-spelling contingency. People produced high-contingency (or lexically common) spellings more often than other plausible but low-contingency spellings. The spellings people produced for vowels varied considerably; there was no sense that they generated only the "major" (or "regular") spellings provided by deterministic sound-to-spelling "rules." Rather, people's spellings reflected the graded sound-to-spelling contingencies inherent in the lexicon (Barry \& Seymour, 1988). Second, there was a conspicuous effect of lexical priming. How people wrote a nonword was strongly influenced, although never completely determined, by the spelling of a preceding rhyming word, and the magnitude of this priming effect was larger for the production of low- than of high-contingency spellings. Third, the priming effect was reduced when an unrelated word intervened between the prime and target nonword, and this reduction was greater for the production of low- than of high-contingency spellings. The first two of these findings have been reported before, but the third is novel and, we submit, advances theories of spelling production.

We have argued that a prime word biases the spelling of a subsequent rhyming nonword by the combination of two factors: First, appropriate spellings are more likely to be selected if their graphemic-level representations have been recently activated, and second, recently activated sound-tospelling correspondences are more likely to be applied when spelling a nonword is required. Graphemic-level effects are short-lived (Perry, 2003); indeed, if graphemic activation lasted too long, the letters used to spell vowels would become unhelpfully overactivated (e.g., Cotelli, Abutalebi, Zorzi, \& Cappa, 2003). The finding that intervening words reduced priming more for low-contingency spellings can be interpreted if we assume that the overall degree of graphemic activation from prime words reflects the summed - and integrated (Rapp et al., 2002) - contributions of both the 
Fig. 1 The priming effects found in the experiment. High-con., high-contingency spelling; Low-con., low-contingency spelling

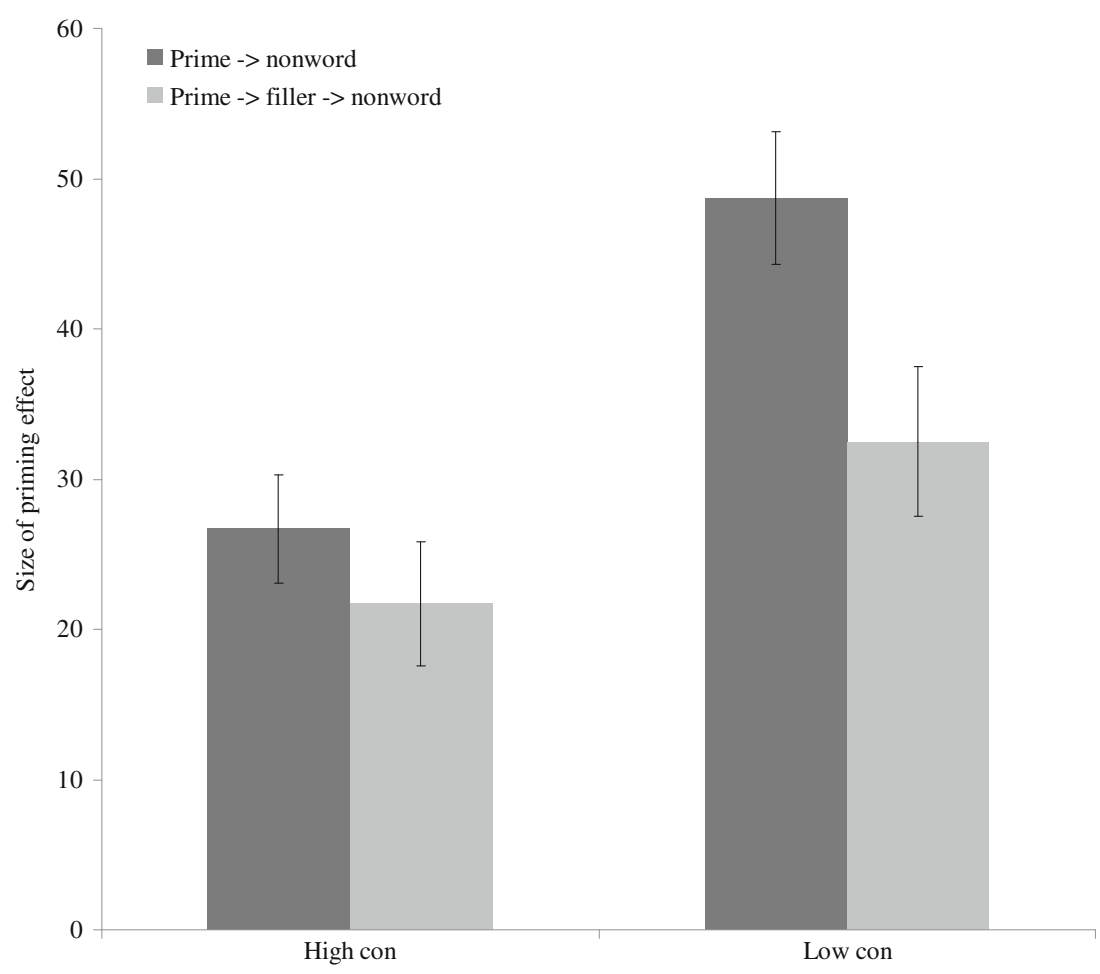

lexical and assembled routes. We propose that the assembled spelling system activates graphemes in proportion to their sound-to-spelling contingencies. Barry and Seymour (1988) suggested that assembled spelling implements a set of probabilistic mappings of vowels to weighted lists of spellings ordered by sound-to-spelling contingency, such as /i:/ => EA (.40), EE (.39), IE (.07), E-E (.05), eight others (.09), where the figures represent baseline probabilities of each spelling being produced derived from their frequencies abstracted from lexical knowledge. The combination of these proposals therefore results in higher levels of graphemic activation from prime words with high- than with lowcontingency spellings. For example, "leaf" lexically activates the graphemes L-EA-F and the assembled route increments this pattern by an additional .40, whereas "thief" activates TH-IE-F but the assembled route increments this pattern by only an additional .07 (and will also activate other conflicting graphemic patterns, such as THEAF and THEEF, by relatively larger amounts). ${ }^{2}$ The presence of an intervening word selectively reduces persisting graphemic activation more than it affects spelling correspondences and, so, has a greater deleterious effect on low- than on high-contingency spellings, which was the pattern of results we observed.

\footnotetext{
${ }^{2}$ The figures of .40 and .07 cited represent the relative additional graphemic activation of spelling alternatives provided by the assembled route that implements sound-to-spelling contingencies. We make no assumption here about the relative contributions of the lexical and assembled routes (or, indeed, whether the extent of lexical activation may be additionally determined by variables such as word frequency).
}

Graphemic persistence also accounts for Folk and Rapp's (2004) orthographic priming effect. For example, the prime "bead" will lexically activate the graphemes B-EA-D, and the assembled route will further increment this pattern by an additional .40. When confronted with the nonword/ped/, the assembled route will activate P-E-D (as /e/ $=\mathrm{E}$ in $90 \%$ of words) but also P-EA-D (as /e/ = EA in $7 \%$ of words), which slightly increases the probability of selecting the preactivated graphemes EA-D. Abrams, Trunk, and White (2008) found that the production of low-contingency spellings in words (e.g., privilege) was primed equally by the prior correct writing of words that shared both orthography and phonology (e.g., sacrilege) and only orthography (e.g., siege) with the target spelling. Abrams et al. suggested that this orthographic priming of word spelling also resulted from the preactivation of target graphemes. However, persisting graphemic activation cannot be the sole cause of the priming of nonword spelling when prime words are not actually written; if it were, both "bead" and "head" should prime spelling/ped/ as PEAD equally, but Folk and Rapp found that priming from rhyming words was three times the magnitude of purely orthographic priming. There must also be the priming of the selection of spelling correspondences.

The mechanism underlying the priming of spelling correspondences

The spelling pattern of a prime word is more likely to be selected when writing a subsequent nonword because the 
activation level of its sound-to-spelling correspondence has been increased. But how precisely does this spelling correspondence priming operate? Previous studies have not fully explained the priming effect within a broader theoretical framework of spelling production, which we shall now attempt here.

The first common point at which information from the lexical and assembled processes converges is the graphemic level. The priming of spelling correspondences must involve segmentation of lexical orthography and the alignment of spelling components to influence assembled spelling. Prime words will be processed in parallel by the lexical and assembled routes, with both activating letters at the graphemic level where there is integration of information from both routes (Rapp et al., 2002).

McCloskey, Macaruso, and Rapp (2006) have proposed that the grapheme level feeds back activation to lexical orthographic representations prior to lexical selection. This feedback would both assist orthographic lexical selection and allow sublexical information to "strengthen the representations of target words and their constituent graphemes" (Folk, Rapp, \& Goldrick, 2002, p. 654). Adopting this general interactive architecture, we make the novel proposal that there is also feedback from the graphemic level to the assembled spelling route (see Fig. 2). When spelling a dictated nonword (e.g., "veef"), the assembled route involves the following

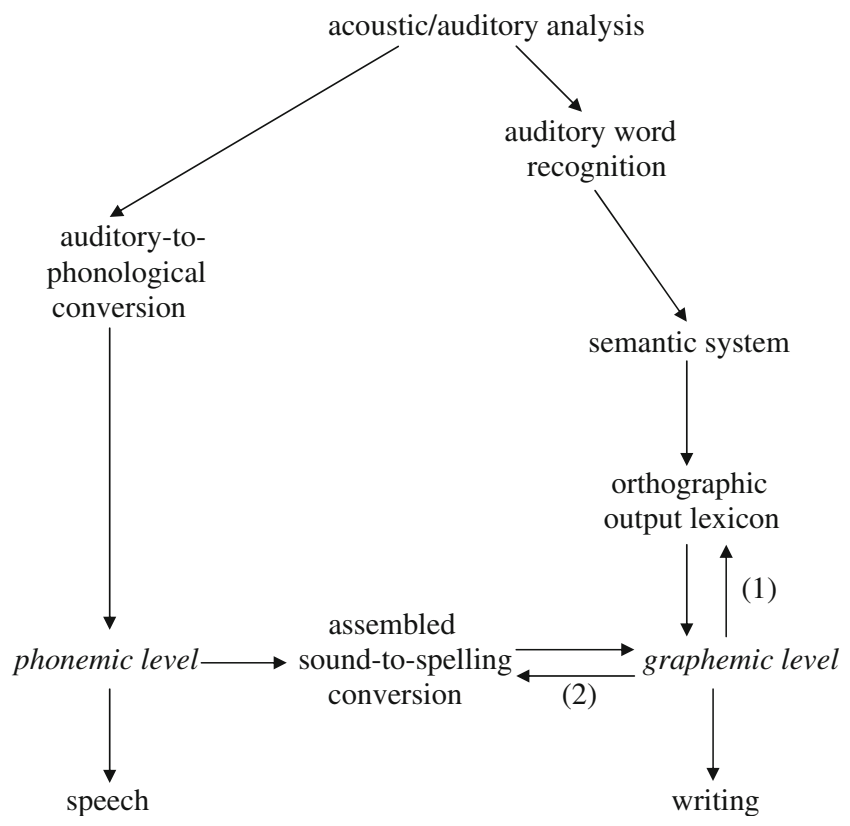

Fig. 2 A model of the spelling production system. This model shows the dual-route processes of spelling, with interactive connections between both (1) the graphemic level and the orthographic output lexicon (as proposed by McCloskey, Macaruso, \& Rapp, 2006) and (2) the graphemic level and the assembled spelling system (which is the novel proposal advanced here) sequence of processes: (1) Auditory-to-phonemic conversion produces an internal phonological form of the stimulus (e.g., /vi:f/); (2) the phonological form is segmented into its constituent phonemes (e.g., /vi:f/ $=>/ \mathrm{v} /$, /i:/, /f/ and, probably, also /i:f/); (3) sublexical sound-to-spelling correspondences of these phonological segments are activated (e.g., $/ \mathrm{v} /=>\mathrm{V}$, /i:/ $\Rightarrow$ EA, EE, IE, E-E, etc., /f/ $=>$ F, and perhaps also /i:f/ $=>$ $\mathrm{EAF}$ ); and (4) activated spellings activate their graphemic forms, which will be integrated with persisting graphemic activation from the prime word. We propose that the resulting pattern of graphemic activation then feeds back to the assembled route to temporarily reweight spelling correspondences. The assembled route applied to the prime word will produce persisting sublexical phonological and grapheme activation. Spelling correspondence priming results from the increased activation of the specific connection between a phonological segment and the graphemic representation of its spelling. As both the phoneme /i:/ and the grapheme EA remain temporarily active, the /i:/ $\Rightarrow$ EA correspondence will be temporarily strengthened (and so "leaf" primes the /i:/ => EA spelling correspondence).

This account predicts that priming will be relatively greater for low- than for high-contingency correspondences, which is precisely what the experiment found. Barry and Seymour (1988) suggested that priming simply added a constant to the weightings of the spelling correspondences provided by the assembled route, but this simplistic account cannot explain our results. Low-contingency spellings were produced only rarely in the free-spelling control condition, and, so, clearly they had greater scope for improvement when primed than more commonly produced highcontingency spellings. (Reitter et al., 2011, make a similar point concerning priming in other domains.) We have characterized assembled spelling as the operation of a set of probabilistic sound-to-spelling correspondences, where the weightings of the spelling alternatives are determined by contingencies abstracted from the lexicon over a lifetime of vocabulary exposure. The low resting activation levels of low-contingency spelling correspondences might be primed either by some proportional degree or by changing the effective rank order of the spelling alternatives offered by the assembled system.

\section{Conclusion}

Spelling novel forms involves coming to terms with the complex sound-to-spelling relationships of English; writers must exploit their predictability where possible (e.g., for consonants) but must also deal with their inconsistencies, especially for vowels. We have advanced an account of the lexical priming of nonword spelling within an interactive 
dual-route model that makes two new proposals: First, persisting graphemic activation from a prime word results from the combined and integrated outputs of both the lexical and assembled spelling processes, and second, there is feedback from the graphemic level to the assembled spelling process.

In general, we suggest that the adult spelling system adapts dynamically in the short term to maximize efficient writing production but quickly returns to normal, because sensitivity to temporary variations in the characteristics of words is unlikely to be persistently useful (and, further, will often produce conflict). When people produce written words, the likelihood of vowel phonemes being repeated is fairly high, and given the inconsistent nature of English orthography, the spellings of the repeated vowels will often be in conflict. (For example, /i:/ occurred in eight words in the preceding sentence (we, likelihood, phonemes, being, repeated, fairly, orthography, and be) and was spelled in five different ways!) Writing English is to be continually confronted by spelling conflict. Skilled adult spellers need to be flexible and, so, will show priming effects; but they also strive for stability, and so the system clears graphemic representations and resets spelling correspondences to normal as expediently as possible.

\section{Appendix}

Table 2 The critical stimuli used in the experiment

\begin{tabular}{|c|c|c|}
\hline High contingency prime & Low contingency prime & $\begin{array}{l}\text { Target } \\
\text { nonword }\end{array}$ \\
\hline dream & theme & /vi:m/ \\
\hline kite & tight & /pait/ \\
\hline crew & glue & /smu:/ \\
\hline poke & folk & /nouk/ \\
\hline see & clique & /ji:k/ \\
\hline boot & fruit & /ju:t/ \\
\hline curl & pearl & $/ \mathrm{m} \partial: 1 /$ \\
\hline rise & pies & /naiz/ \\
\hline sealed & field & /ti:ld/ \\
\hline go & dough & /klou/ \\
\hline good & could & /tud/ \\
\hline pork & talk & $\mid \mathrm{z}>: \mathrm{k} /$ \\
\hline pose & goes & /vouz/ \\
\hline beef & thief & /vi:f/ \\
\hline burn & learn & /wo:n/ \\
\hline hide & dried & /smaid/ \\
\hline
\end{tabular}

\section{References}

Abrams, L., Trunk, D. L., \& White, K. K. (2008). Visual and auditory priming influences the production of low-frequency spellings. Reading and Writing, 21, 745-762.

Barry, C. (1992). Interactions between lexical and assembled spelling in English, Italian and Welsh. In C. Sterling \& C. Robson (Eds.), Psychology, spelling and education (pp. 71-86). London: Multilingual Matters.

Barry, C. (1994). Spelling routes (or roots or rutes). In G. D. A. Brown \& N. C. Ellis (Eds.), Handbook of spelling: Theory, process and intervention (pp. 27-49). Chichester, U.K.: Wiley.

Barry, C., \& De Bastiani, P. (1997). Lexical priming of nonword spelling in the regular orthography of Italian. Reading and Writing, 9, 499-517.

Barry, C., \& Seymour, P. H. K. (1988). Lexical priming and sound-tospelling contingency effects in nonword spelling. Quarterly Journal of Experimental Psychology, 40A, 5-40.

Burden, V. (1989). A comparison of priming effects on the nonword spelling performance of good and poor spellers. Cognitive Neuropsychology, 6, 43-65.

Campbell, R. (1983). Writing nonwords to dictation. Brain and Language, 19, 153-178.

Campbell, R. (1985). When children write nonwords to dictation. Journal of Experimental Child Psychology, 40, 133-151.

Cotelli, M., Abutalebi, J., Zorzi, M., \& Cappa, S. F. (2003). Vowels in the buffer: A case study of acquired dysgraphia with selective vowel substitutions. Cognitive Neuropsychology, 20, 99-114.

Cuetos, F. (1993). Writing in a shallow orthography. Reading and Writing, 5, 17-28.

Ellis, A. W. (1982). Spelling and writing (and reading and speaking). In A. W. Ellis (Ed.), Normality and pathology in cognitive functions (pp. 113-146). London: Academic Press.

Folk, J. R., \& Rapp, B. (2004). Interaction of lexical and sublexical information in spelling: Evidence from nonword spelling. Applied PsychoLinguistics, 25, 565-585.

Folk, J. R., Rapp, B., \& Goldrick, M. (2002). The interaction of lexical and sublexical information in spelling: What's the point? Cognitive Neuropsychology, 19, 653-671.

Houghton, G., \& Zorzi, M. (2003). Normal and impaired spelling in a connectionist dual-route architecture. Cognitive Neuropsychology, 20, 115-162.

Jones, A. C., Folk, J. R., \& Rapp, B. (2009). All letters are not equal: Subgraphemic texture in orthographic working memory. Journal of Experimental Psychology: Learning, Memory, and Cognition, 35, 1389-1402.

Kreiner, D. S., \& Gough, P. B. (1990). Two ideas about spelling: Rules and word-specific memory. Journal of Memory and Language, 29, 103-118.

McCloskey, M., Macaruso, P., \& Rapp, B. (2006). Grapheme-to-lexeme feedback in the spelling system: Evidence from a dysgraphic patient. Cognitive Neuropsychology, 23, 278-307.

Morton, J. (1980). The logogen model and orthographic structure. In U. Frith (Ed.), Cognitive processes in spelling (pp. 117-133). New York: Academic Press.

Nation, K., \& Hulme, C. (1996). The automatic activation of sound-letter knowledge: An alternative interpretation of analogy and priming effects in early spelling development. Journal of Experimental Child Psychology, 63, 416-435.

Perry, C. (2003). Priming the rules of spelling. Quarterly Journal of Experimental Psychology, 56A, 515-530.

Rapp, B., \& Caramazza, A. (1997). From graphemes to abstract letter shapes: Levels of representation in written spelling. Journal of 
Experimental Psychology. Human Perception and Performance, 23, 1130-1152.

Rapp, B., Epstein, C., \& Tainturier, M.-J. (2002). The integration of information across lexical and sublexical processes in spelling. Cognitive Neuropsychology, 19, 1-29.

Reitter, D., Keller, F., \& Moore, J. D. (2011). A computational cognitive model of syntactic priming. Cognitive Science, 35, 587-637.

Scarborough, D. L., Cortese, C., \& Scarborough, H. S. (1977). Frequency and repetition effects in lexical memory. Journal of Experimental Psychology. Human Perception and Performance, 3, 1-17.
Scheepers, C. (2003). Syntactic priming of relative clause attachments: Persistence of structural configuration in sentence production. Cognition, 89, 179-205.

Tainturier, M.-J., \& Rapp, B. (2000). The spelling process. In B. Rapp (Ed.), The handbook of cognitive neuropsychology (pp. 263-289). Philadelphia, PA: Psychology Press.

Ziegler, J. C., Stone, G. O., \& Jacobs, A. M. (1997). What is the pronunciation for -ough and the spelling for $/ \mathrm{u} /$ ? A database for computing feedforward and feedback consistency in English. Behavior Research Methods, Instruments, \& Computers, 29, 600-618. 